\title{
A politica florestal para o desenvolvimento da Amazonia
}

João Murça Pires ( ${ }^{*}$ )

\section{A FLORESTA AMAZONNICA E O SEU DESENVOLVIMENTO}

Tal política visa a estabelecer um equilíbrio entre os diversos problemas existentes na região, alguns paralelos, outros convergentes ou interrelacionados e até conflitantes. Envolve matéria muito complexa, de difícil decisão e cuja solução tem caráter de relevante urgência. Envolve interesses nacionais e internacionais, como o próprio bem estar da humanidade.

O problema das florestas não pode, entretanto, ser resolvido isoladamente poryuante ele está intimamente ligado ao problema agrícola. Os projetos agrícolas e agropecuários implicam diretamente na interferência do homem sobre a floresta, com resultados que atingem profundamente o problema florestal e até a própria existência ou o desaparecimento destas mesmas florestas. Assim sendo, para uma análise do problema como um todo, não se pode deixar de analisar o padrão de vida na zona rural de maneira ampla, aumento da renda bruta e sua distribuição.

A zona rural é, por excelência, a zona agrícola e não se poderá obter uma política fiorestal vigorosa num ambiente depauperado.

Por outro lado, a indústria florestál tem suas raízes nos centros urbanos e, pelo menos, em termos de agricultura, não se pode conceber um estágio adiantado na zona rural sem que haja um paralelo desenvolvimento da zona urbana e das zonas periféricas às cidades.

ELEVAÇÃo DE NÍVEL DA VIDA No MEIO RURAL

A população rural, de atividade essencialmente agrícola, é composta de trabalhadores não especializados (braçais), cujo padrão de renda geralmente está abaixo do salário mínimo, têm uma legislação previdenciária especial (FUNRURAL) inferior e, além do mais, a maioria não está filiada a qualquer dos sistemas previdenciários e nem possui Carteira Profissional. No entanto, o que até parece um contra-senso, há maior procura do que oferta de braços. É difícil encontrar-se trabalhador rurai na Amazônia porque a maioria prefere ser auto suficiente, produzindo o que precisa e sujeitando-se a um padrão extremamente baixo de vida, mas que não é propriamente indicação de apatia ou indolência. Como assalariado, teria menos liberdade e não conseguiria melhorar seu padrão de vida.

A atividade do produtor agrícola não está sendo compensada e isto depende de muitos e intrincados problemas, tais como baixa fertilidade das terras, intemperismo e exaustão dos nutrientes, preço dos adubos e a falta de exemplos a serem seguidos. Se for ensinada a maneira certa de fazer as coisas ou, se alguns agricultores estiverem tendo bons resultados, serão certamente imitadơs, como aconteceu com a colonização das zonas férteis. como as terras roxas ao norte do Paraná. Enquanto houve bons resultados evidentes, 0 governo não precisou incentivar e atć teve problemas para frear o movimento, com a ocorrência de invasões, problemas de domínio, etc. Ao contrário, a colonização de zonas pobres, mesmo com incentivos, tem resultado em inumeros fracassos. Desnecessário se torna citar exemplos, à semelhança do que aconteceu com a Zona Bragantina no Estado du Pará ou com o conjunto de casas abandonadas, completamente vazias que existe logo acima da Vila Militar, de Oiapoque, no Amapá. Aqui. além das terras muito pobres, foram trazidos colonos nordestinos, que não sabiam lidar com as difíceis e perigosas cachoeiras do rio, que consistia na única via de transporte.

(") - Museu Paraense Emílio Goeldi, Belém. 
A coionização bragantina, faixa entre Belém e o litoral paraense, ficou altamente desvalorizada com a colonização. A pujante floresta foi extinta, substituída por capoeiras desvalorizadas e o elemento básico da colonização - a Estrada de Ferro Belém-Bragança, com locomotivas movidas à lenha, consumiu grande parte da floresta.

Até hoje ainda perdura, como rendimento principal, o comércio de carvão para uso doméstico e a produção de farınha de mandioca, num regime em que o produtor consonie quase tudo que produz.

Nos últimos tempos, houve sucessos localizados, com a cultura da Pimenta-do-Reino, porque em solos muito pobres, a agricultura tem que ter obrigatoriamente um padrão mais elevado, que só é conseguido quando se trata de um produto cujo preço unitário é mais alto, como é o caso da Pimenta-dc-Reino. Quem usar adubos na cultura de arroz, mandioca ou milho estará fadado a ter prejuízos.

Este fato explica o sucesso havido com a colonização nipônica de Tomé-Açu que se dedicou à cultura da Pimenta-do-Reino, tornando urn campo de concentração dos tempos da segunda querra mundial num dos municípios mais progressistas da Amazônia.

A faixa periférica às cidades, que se usa chamar de cinturão verde, é mais fácil de se colonizar porque se adapta a produtos de maior preço, tais como hortaliças, frutas, leite e pequenos animais domésticos.

Os investimentos latifundiários e os que envolvem grandes recursos, no geral subvencionados, não raro também fracassaram, nalguns casos por planejamentos involuntariamente mal feitos, em outros, por questão de especulação, mas sempre ocasionando a substituição de f́lorestas por capoeiras.

\section{ELIivação DE NÍVEL DA VIDA URBANA}

Como já se disse acima, melhorar o padrão da faixa periférica às cidades é menos difícil porque se podem cultivar produtos de valor comercial mais alto.

Há, entretanto, outros problemas muito mais difíceis de resolver-se nas cidades, tais como a ocupação humana de áreas impróprias para habitação, alagados, condições sanitárias, transporte, etc..

Os desajustes na cidade se agravan mais quando se trata do homem do interior que é deslocado para os centros urbanos onde ele se encontra despreparado para concorrer pela sobrevivéncia.. No interior, o sertanejo, quase como o indigena, vive em relativo equilíbrio com a natureza.

São problemas, portanio, interligados e que finalmente são agravados pelo aumento da densidade demográfica, não só pelo aumento da própria população como também pela imigração de outras áreas. Isto se faz sentir, fortemente, nas zonas interioranas onde há pressão de interferência do homem, como está acontecendo nos limites leste e sudeste da Amazônia (frontoira de pioneirismo).

Há a considerar ainda que a grande maioria da populaçũo vive nos centros urbanos $e$, principalmente, nas duas maiores capitais. Portanto, a solução dos problemas urbanos é a solução da maior parte dos problemas de toda a região.

Quanto ao aspecto florestal, entretanto, os problemas da agricultura ocupam lugar de muita relevância e têm que ser tratados concomitante e integradamente.

Há a considerar que alguns problemas de outras regiôes atingem diretamente a evolução de fatos na Amazônia. Assim é que os programas de aproveitamento dos cerrados que estão ativamente sendo estudadios atualmente em Brasília pelo Centro Nacioiıal de Pesquisa de Cerrado, sob a jurisdição da EMBRAPA, são programas que interessam de perto a Amazônia porque poderão desslocar uma parte da pressão exercida pelo movimento de colonização. Aquela região tem um menor patrimônio exposto, no que concerne à interferência do homem sobre a natureza. É uma região já bastante perturbada, de mais fácil acesso e com uma menor complexidade de problemas a serem resolvidos. $O$ seu estudio pode ser feito em menor tempo, graças à facilidade de acesso.

A cultura do arroz no cerrado vem, por exemplo, tomando grande incremento e já ocupa grandes áreas de agricultura mecanizada na região entre Xavantina e São Felix, a 
oeste do Araguaia, justamente ao lado dos grandes empreendimentos agropecuários que se estão implantando na mata amazônica que fica a oeste. O beneficiamento de arroz, em nível adiantado de industrialização, vem sendo feito "in loco".

Mesmo dentro da região amazônica, há certas áreas não florestais que enfrentam menores problemas para o aproveitamento. Assim, podem ser classificados os campos de várzea do Baixo Amazonas onde a rizicultura pode ser promissora. Alguns campos ae Roraima, com forte periodismo, com uma estação definidamente seca, devem ser próprios à cotonicultura. Roraima conta com a vantagem de ter as estações (seca e úmida) invertidas com relação ao restante da Amazônia Brasileira $e$ isto pode propiciar a colheita de certos produtos fora de tempo, alcançando maiores preços.

Os problemas do aproveitamento óa flo resta amazônica são tantos e, em grande parte ainda não resolvidos, que há uma grande vantagem dentro deste contexto, que é a possibilidade de se ganhar tempo.

\section{MANEJO DA FLORESTA MEDIANTE}

A UM EQUILÍBRIO RACIONAL

Este é o ponto vital de o todo o complexo, onde ainda perduram muitas questōes, tais como: se os processos que estão sendo empregados atualmente teriam sofrido uma avaliação precisa, para se saber a proporçäo de defeitos que carregam; se as áreas de interferência (colonizadas) foram valorizadias, ganharam ou perderam riqueza, esta considerada eni caráter imediatista ou relativamente ao futuro, à geração que nos sucederá; se existem atualmente conhecimentos suficientes sobre a tecnologia a ser usada no aproveitamento racional da floresta, quer seja a região considerada como um todo ou quanto a áreas particularizadas. Qual o teor de risco que corre o patrimônio científico, físico e biológico. na dependência de possíveis erros de manejo, de resultados irreversiveis e impassíveis de correção? Se o acelerado programa rodoviário que fơi dirigido à regiáo, apesar das indiscutiveis vantagens, considerado no seu todo ou em parte, não poderia conter implicações de efeito altamente desvantajoso.

Sabe-se que a maior parte da região tem terras fracas, que a pujança da floresta e a magnitude da sua biomassa advêm de um processo evolutivo demorado, que chegou a um estágio de clímax, de tal sorte que, a maior parte dos nutrientes se encontra no corpo das próprias plantas e não primordialmente no solo. Nas condições de alta umidade, não há o efeito do fogo e a floresta, com a sua manta orgânica do solo, possui um mecanismo alta. mente especializado para evitar perdas de nutrientes por lavagem. O seu ecossistema resulta entretanto num organismo frágil, de um modo geral, quando submetido à interferência do homem.

Disto tudo se conclui que não existem ainda conhecimentos suficientes sobre a floresta aniazônica, sobre sua estrutura, como funciona e qual o melhor processo para a sua utilização.

Daí, os cuidados que se deve ter nos processos de interferência e manejo. sendo justificável a elaboração de intensos projetos pilotos de manejo. Não parece entretanto aconselhável a implantação de projetos muito ainplos e definitivos. Este deve ser urn dos objetivos de tal política.

\section{DFFINIÇÃo RACIONAL DAS PRIORIDADES}

Dentre as inúmeras questões a resolver, certamente deve haver um escalonamerito de imçortância.

$\mathrm{Na}$ situação atual em que a humanidade vive em fase de crise, enfrentando dificuldades, principalmente num país em desenvolvimisnto, é natural que os problemas imediatos, tanto quanto possível, devem ser tratados com prioridade.

Em termos de nação, sempre existem problemas ou projetos que produzem resuitados a curto prazo e outros que requerein tempo e, em muitos casos envolvem um teor de sacrifício da geração presente, entre um extremo e outro. Assim, os problemas de alimentação são imediatos, a próspecção de petróleo já leva um teor de investimento para o futuro, como sacrifício do presente que não é de folga. A abertura da Rodovia Belém-Brasília re- 
solveu muitos problemas na região, mas a $\mathrm{Pe}$. rimetral Norte, uma obra de alto custo, cortancio regiões, desabitadas e sem previsão de povoamento, logicamente é um ônus para a geração presente. Também a velocidade com que as obras são executadas muitas vezes influi pesadamente no seu custo.

Nem sempre é fácil decidir-se sobre prioridades. As represas para produção de eietricidade, como a de Tucuruí, demoram álguns anus para dar produção e pesam consideravelmente sobre o orçamento do presente, entretanto, o alto significado da obra acoriselha a sua execução, mas existem outros casos em que a velocidade com que se procurou executar as obras de retorno demorado, principalmente em governos passados, pesou ciesproporcionalmente sobre a geração presente. Fáremos referência a um exemplo.

Em 1974, em nosso trabalho de exploração botânica, utilizávamos as facilidades de transporte oferecidas pelo Projeto RADAM e verificamos o grande esforço que se fazia para levar equipamentos e material pesado pelo rio Branco, na época da seca. Barcos encalhados aqui e acolá, esforçavam-se para chegar até Boa Vista porque as diversas companhias que construíram a Perimetral Norte tinham prazo estipulado para a rápida entrega dos diferentes trechos em construção. Se se espe. rasse um pouco mais o rio subiria suas águas e tudo seria mais fácil.

Entre Caracaraí e o rio Ajarani, em plena floresta (aliás de terra roxa), encontramos alguris trabalhadores cortando madeira serrada para alguma obra. Desejosos de saber quais as madeiras úteis da região, perguntamos qual era a espécie de madeira que estava sendo cortada, tendo como resposta que se tratava de Peroba de São Paulo. Isto porque as empresas tinham data certa para entregar as obras, não podiam confiar nas probabilidades e, por segurança, traziam tudo de fora como se fossem descer na lua.

No entanto, não seria fácil explicar a utilidade atual da Perimetral Norte entre Roraima e Cucuí, na fronteira com a Venezuela e a Colômbia, num trecho desabitado, onde nem gente e nem material existia para ser transitado.
Assim sendo, definir racionalmente as prioridades, deve ser um dos objetivos da politica florestal.

No caso das vias de comunicação, existem ainda outras implicações a serem consideradas, como seja, a ativação exagerada da pressão colonizadora.

\section{OCUPAÇÃO RACIONAL DA FLORESTA}

Em termos do que já foi exposto, a linha mestra de uma política racional deveria ter em mira a obtenção do máximo possível de dados sobre a floresta primeva, antes que ela venha a ser transformada e substituída por uma outra entidade em caráter irreversível. Para isso, seria necessário não somente um programa, mas, um programa que não sofresse desvio na sua conduçẩo.

\section{PromoçÃo Do CONHECIMENTO DA REGIÃo E DE SEUS PROBLEMAS PORMENORIZADOS}

Não resta dúvida de que a floresta tropical únida da Amazônia, um inestimável patrimônio brasileiro e da humanidade, à semelhança do que acontece em outros paises e em outras regiões, está correndo grande risco, não somente de sofrer sério distúrbio biológico no seu ecossistema mas também está passível de extinção. Só nos últimos tempos, o homem se apercebeu de que a sua interferência sobre a natureza da terra está causando uma perigosa degradação do meio ambiental em que ele próprio vive. Há fenômenos que estão acontecendo e demoram para ser percebidos e este é um deles e talvez o mais grave.

$\mathrm{Na}$ história da evolução dos seres vivos, houve um estágio em que o homem se avantajou sobre outros animais, por explorar e desenvolver os mecanismos da aprendizagem. Arites disso, a evolução se dava pela ácomodação às variações do meio ambiente, graças ao instinto, às especializações herdadas $e$ transmitidas aos descendentes. O novo sis tema trouxe grande vantagem adaptativa porqu€ permitiu a transmissão de especializações não somente aos descendentes mas também aprendizagem independente da dependência genética. Permitiu ainda que os conhecimen. tos pudessem ser gradativamente somados, 
com o aparecimento da linguagem e da escrita e o surgimento da tecnologia, a capacidade de o homem modificar o seu próprio ambiente.

A grande vantagem evolutiva alcançada pelo homem começa agora a ser questionada, com indícios de que o sistema poderia ser concuuzido a um fim catastrófico. A explosão demográfica quebrou o equilíbrio e é vista como um perigo que deve ser controlado. O homem antigo e os nossos índios viviam em equilíbrio com a natureza, tinham a densidade demográfica regulada pelos recursos disponíveis na floresta.

Isto todos hoje sabem, mas precisa ser repisado, porque é assunto relevante que está abalando a opinião em todo o mundo, existindo mesmo o grupo dos que são classificacios de "ecologistas". Entre ecologislas e imediatistas, há posições extremas e exageradas mas, o assunto está sendo levantado $\mathrm{em}$ todo o mundo e precisa ser considerado dentro de um equilibrado bom senso. Em 1976, entre 11 e 13 de maio, houve um congresso no New York Botanical Garden, nos Estados Unidos. sobre as espécies e áreas ameaçadas de extinção, cujas contribuições foram reunidas no livro Extinction is Forever (Prance \& Elias, 1977) e outros encontros e reuniões têm sido programados para tratar do importante assurito.

A paisagem da floresta tropical úmida é espalhada pelos diversos continentes e em todos estes lugares ela guarda grande semelhança fisionômica, apesar da grande diversidacie na composição florística. E é uma formação muito antiga. Segundo Richards, pelo exame de fósseis encontradós na Malásia e em outros lugares, há evidências de que formações com a fisionomía da pluviosilva tropical de hoje existiam desde o cretáceo que terminou há 60 milhões de anos, deve ter tido períodos de expansões e contrações, deve ter sofrido muitas formas de variação em sua evolução, no entanto, mesmo no passado muito remoto sua aparência devia ser muito semelhante à atual. Teoricamente, se fosse feita uma fotografia da terra, numa faixa de $10^{\circ}$ ao norte e ao sul do Equador, há 200 anos, apareceria uma faixa verde. Se essa fotografia fosse feita há 1.000 anos, essa faixa não deveria ser muito diferente, entretanto, neste século ela sofreu um forte trauma- tisino, uma rápida mudança. Fotografias de satélite mostram que ela já não é mais contínua e na última década a transformação se acelerou extraordinariamente. Manchas de florestas pluviotropicais ainda restam na Amazônia, na África, na Ásia, mas no fim deste século, muito pouca coisa vai sobrar e esta destruição de florestas com milhões de anos de iclade é um dos fatos mais extraordináriơs que já aconteceram na história. Ainda segundo Richards (idem), no fim deste século muito pouca coisa vai sobrar e a sua destruição terminará antes da destruição das florestas temperadas, um extraordinário marco na história da conquista do homem sobre a terra, que não comprometerá somente o homem mas toda a biosfera.

No entanto, estas florestas tão antigas e fadadas à destruição são ainda muito mal conhecidas. A sua preservação se justifica muito mais do que a conservação e a recuperação de outros monumentos históricos.

No caso da hiléia amazônica, não se pode avaliar com precisão as espécies ameaçadas. no que concerne à botânica, e o assunto deve ser posto em termos de áreas ameaçadas. Isto porque a região é muito mal conhecida, o seu interior não foi penetrado e nem sabemos ao certo quais são as espécies que existem e onde elas se encontram. No caso dos animais, há espécies conhecidas em evidente risco de extinção.

Numa época em que o homem tem gasto astronômicos recursos financeiros para pesquisar se existe vida fora da terra, é um contra-senso e um absurdo admitir-se que as formas de vida da terra sejam negligenciadas, mesmo quando em perigo de extinção.

Há ainda a considerar, que mesmo dentro do conceito utilitarista, a floresta amazônica apresenta um portentoso recurso econômico que não pode ser desperdiçado por um manejo deficiente. Em termos de energia há uma potencialidade imensa. Nas vizinhanças de Manaus, Klinge e Rodrigues $(1968,1971)$ calcularam que a biomassa da floresta equivale a cerca de mil toneladas por hectare. A Amazônia Brasileira tem sido estimada em cerca de 350 milhões de hectares e, se considerada a metade da média calculada por aqueles autores, a sua biomassa envolveria 175 bilhões 
de toneladas. Já tem sido demonstrado que grande parte do carbono do mundo se encontra imobilizada no corpo da floresta amazônica, incluindo-se nela a parte extra-brasileira.

$\mathrm{Na}$ presença de dados criteriosos, isentos de exageros, há evidências de que os assuntos relativos ao aproveitamento da floresta amazônica têm que ser desenvolvidos com moderação e que na sua condução deve ser estabelecida uma fase preparatória de intensas pesquisas, para que se possa recolher 0 máximo possível de dados sobre o conhecimento do seu ecossistema como um todo.

O programa de exploração botânica e zoológica é da mais alta prioridade. Dará como resultado não somente a produção de conhecimentos a curto prazo como também propiciará o armazenamento de dados (como são os espécimes herborizados) para estudos a serem realizados no futuro, mesmo após grandes transformações terem-se verificado na atual paisagem. Um exemplo disto é o fato de que o maior repositório de dados sobre a flora da Amazônia não se encontra no Brasil e sim nos herbários de Kew Gardens (Inglaterra), New York Botanical Garden, Smithsonian Institution. A maior de todas as fontes, o Herbário de Berlim, foi destruído durante a guerra. Isto demonstra também a vantagem do intercâmbio

A delimitação de sub-regiões florísticas, faunísticas ou ecológicas é necessária tanto para a biologia fundamental como para a exploração econômica. Torna-se indispensável para a localização das reservas que se devem preservar. Os levantamentos exploratórios do Projeto RADAMBRASIL precisam ser pormenorizados.

Para tal zoneamento, será preciso aperfeiçoar o sistema de inventários que não deve estar orientado unicamente à metragem de madeira e deverá ser feito somente por entidades de conceito reconhecido. Atualmente os inventários florestais em sua maioria são destituídos de valor e acarretam enormes despesas, executados principalmente por escritórios de planejamento e assessoria.

Como subsídio para o programa de levantamentos e prơspecções, será necessário in- crementar o treinamento de pessoal em taxonomia, em identificação de lenho e em identificação de pólem.

Nas áreas típicas, deverão ser demarcadas as reservas que precisam ser conservadas como amostras representativas. Com localização mais acessivel, devem ser estabelecidos também os hortos de introdução (plantas vivas) e os herbários. Os três elementos reservas, hortos e herbários são peças que se completam.

Herbário é uma instituição cara e somente pode ser criada junto aos grandes centros. As despesas que envolvem são mais pesadas do que no geral se supõe, daí a vantagem do intercâmbio e de se dispor de espécimes para estudo em herbários de outros países.

Sobre esse tópico, é bom realçar que o Brasil não possui um herbário sequer que possa ser classificado como isento de deficiências. Há herbários muito valiosos como o do Jardim Botânico do Rio de Janeiro e do Museu Nacional que não somente não estão em padrão internacional ou aceitável, mas em decadência por falta de recursos. São instituições que possuem competentes pesquisadores e coleções altamente valiosas que se depreciam por não contar sequer com um sistema adequado para acomodação desse material.

A criação do Museu Nacional de Brasília seria outra providência altamente recomendável. Deverá incluir herbário e horto. Planejado de início, em alto padrão, um herbário em Brasília contará com as vantagens de um clima seco que facilita a conservação dos espécimes. Já existe uma valiosa base inicial que é o Herbário da UnB e seu patrimônio poderia ser, de início, altamente enriquecido com o subproduto da reorganização e atualização dos herbários do Museu Nacional e do Jardim Bo. tânico do Rio. Esses dois herbários, ambos, não separam suas duplicatas que estão incluídas no herbário geral. Numa reorganização, um elemento muito caro é o conjunto de a:mários especialmente construídos para acomodação dos espécimes e, portanto, para diminuir o custo, as duplicatas terão que ser separadas e o seu melhor destino é o intercâmbio cơm outras Instituições. Incluem-se coleções antigas de inestimável valor. 
Retornando ao caso das reservas, torna-se altamente recomendável que um levantamento pormenorizado seja feito em torno das cidades, principalmente as grandes, para verificar quais as áreas de florestas que existem, ainda não perturbadas ou pouco perturbadas. transformando-as em reservas biológicas. Isto é importante e urgente, constituirá um eiemento de valor para complemento dos herbários e como subsidio para as Universidades treinarem seus alunos, principalmente ao nível de pós-graduação.

Na região de Belém, por exemplo, uma das capitais da Amazônia, já não mais existem matas virgens de terra firme a menos de uma centena de quilômetros. Encontram-se apenas áreas inundáveis que não foram usadas para a agricultura. Neste particular, Belém fica em condições muito inferiores à cidade de São Paulo que conta, entre outras, com as florestas da Cantareira.

As pesquisas agrotécnicas, solos, fertilidade, logicamente são elementos indispensáveis e estão aqui apreciados de relance porque, para a sua implantação, o país já dispõe de estrutura básica firmada que depende apenas de incentivo e remanejo, no Ministério da Agricultura.

\section{DISCIPLINAÇÃO E FISCALIZAÇÃO DO \\ ANDAMENTO DOS PROJETOS}

As diretrizes encontram aqui uma atribuição extraordinariamente difícil. É muito mais fácil elaborar um bom projeto, nestes casos, do que conseguir que ele tenha boa execução, não se desviando do roteiro. Os exemplos disso estão por toda parte. Nós possuímos boas leis, código florestal, proteção da fauna e da flora, mas é muito difícil fiscalizar sua aplicaçẩo.

A própria cidade de Brasília, pré-delineada, quando foi implantada, viu surgir ao redor de si um grande número de favelas, de invasões, elementos perturbadores que logicamente não estavam no projeto.

O Parque Nacional de Brasília, refúgio de muitas espécies em extinção como Ema, Siriema, Lobo-guará, além de plantas, anualmente tem a vegetação incendiada. Isto, para falar-se de coisas que estão em volta da sede do Governo. A Amazồnia brasileira, com três e meio milhões de quilômetros quadrados de áreas inacessíveis constitui problema ainda maior para a sua fiscalização.

Torna-se necessário portanto que seja criada uma estrutura eficiente de fiscalização que os órgãos de planejamento certamente terão que instituir. Só assim se poderá evitar distorções no uso da mata e da terra, ampliação das capoeiras e das áreas de cultura abandonada, pastagens invadidas por "juquirá", tudo isto em prejuizo de novas áreas de matas incendiáveis, porque as terras são novas ou desprovidas de plantas invasoras.

As áreas invadidas, deterioradas, abandonadas, devem ser agravadas com altas taxas que desencoragem a sua manutenção e, enquanto existirem estas áreas, certamente, nāo se justifica que planejamentos sejam elaborados para aproveitamento de outras áreas cobertas de floresta. Certamente, que um criador que tem como única ferramenta e único manejo a caixa de fósforo e o fogo, não deve ter acesso aos órgãos de financiamento e deve pagar pesados impostos.

O problema é difícil, mas se poderá fazer muito nesse rumo.

\section{POLITICA FLORESTAL}

\section{AValiação Do ESTAdo ATUAL DE INTERFERÊNCLA NA FLORESTA}

Há atualmente, alguns elementos de acompanhamento de como a paisagem se modifica, com o uso de radar, satélites, etc. Mas isto não é suficiente. É preciso que exista um organismo que possa utilizar-se desses elementos e verificar no solo, "in loco", o que está acontecendo: as transformações que estão se dando no ambiente, nas condições sanitárias, na composição das águas, quem são os donus das áreas abandonadas e a amplitude dessas áreas. Trata-se de um projeto amplo, difícil mas, muito interessante. É preciso que se fique sabendo o que está acontecendo como os grandes e pequenos investidores, com as áreas de pressão colonizadora, ao redor das minas e das represas, ao longo das estradas e dos rios. É necessário que se tenha uma avaliação da interferência que já se verificou e que se observe se as áreas interferidas au- 
mentaram suas riquezas ou diminuiram de valor. Torna-se imperioso estudar um jeito de corrigirem-se os eventuais defeitos e aproveitar as vantagens da experiência adquirida.

\section{Atualização Da POLítica dos INCENTIVOS}

A política atual de incentivos somente fornece ajuda aos grandes investidores. As propostas para investimentos têm que ser acompanhadas de um conjunto de formalidades, que somente quem tem recursos pade atender, utilizando-se de uma estrutura de assessoria. Grande parte das peças exigidas são elementos teóricos relativos à análise da situação atual, mercado, projeção futura, etc. elementos de difícil elaboração e pouca precisão, cujo maior efeito é tornar a exposição bem apresentável, e impressionável. Como há pormenores sobre uma parte da floresta a ser preservada, há exigência de um inventário florestal.

Isto deu órigem a que muitos escritórios de planejamento e assessoria fossem organizados, como uma inovação muito rendosa. Alguns desses escritórios são locais outros situados no sul do país.

Os inventários florestais que se realizam por exemplo, têm muito boa apresentação, contêm elaboração executada por computadores, análises estatísticas, e em alguns casos utilizam até helicópteros. Mas todos eles são baseados em dados imprecisos: os nomes das plantas obtidos por mateiros capazes de atribuir ou inventar nomes vuigares, que são comparados com listas gerais pré-existentes de nomes científicos.

E uma realidade que a identificação de plantas na Amazônia é muito difícil porque as árvores são altas, os troncos grossos, as copas densas e pouco visíveis e a grande maioria das espécies não têm nomes vulgares. Os nomes vulgares não são constantes de lugar para lugar. Isto torna impossível a identificação sem a coleta de amostra, mesmo pelos especialistas e práticos mais competentes.

E sabido que um estudo por amostragem. por princípio, tem que se basear em amostras bem estudadas, dados preciosos para que se possa extrapolar para a compreensão do todo. Amostragem mal feita é absurdo. A identifi- cação é um elemento básico porque não se pode avaliar uma vegetação desconhecida sem o perigo de incidir em erros de identificação, que pociem ultrapassar $90 \%$.

A computação eletrônica não melhora os dados com que trabalha; ela apenas torna sua elaboração mais sofisticada. Nestes casos, o seu valor porém, é de puro enfeite.

Demoramós nesta apreciação porque é uma minúcia que envolve pesadas despesas. Os próprios órgãos oficiais quando pretendem estabelecer um planejamento em certa região, costumam exigir estes tipos de inventários altamente dispendiosos e muito atrativos para os escritórios de planejamento.

O critério de trabalhar-se com grandes investidores torna mais fácil a fiscalizaçãc, e diminui o número de empreendimentos. Mas se forem percorridas as zonas de pressão coionizadora ccmo as regiões a oeste do Araguaia e sul de Mato Grosso, encontram-se enormes extensões de áreas, antes florestais, agora abandonadas e transformadas em capoeira, na maioria em pastagens abandonadas. Há certas plantas invasoras (juquiras) muito agressivas. Certas Compositae conhecidas como "Assapeixe" são causa de abandono destas pastagens.

Há clareiras enormes na mata, algumas abrangendo dezenas de milhares de hectares de pastagem.

Nos casos das pastagens denominadas "invernada" não se visa a criação de gado, somente a engorda. O gado é trazido continuamente, engordado e então retirado.

No sistema de invernadas, a situação sanitária é das piores. Com gado entrando e saindo continuamente, torna-se impossível o controle sanitário. A vacina contra aftose é importante e tem que ser feita. O controle e os cuidados contra brucelose, por outro lado, não são interessantes para o investidor porque não se trata de gado de criação. É perigosa para o homem mas não traz prejuízo ao dono da invernada.

As pastagens às vezes abrangem imensas áreas completamente descortinadas, sem subdivisões, sem deixar uma só árvore de sombra. As sedes, no geral, não contam com pomares e outras instalações que visam ao 
homem. A subdivisão das pastagens, em geral é deficiente, dificulta o manejo e facilita a invasão de plantas agressivas e indesejáveis.

Em muitos casos as derrubadas visam à especulação, uma forma de garantir o domínio da área, um atestado de ocupação.

Assim sendo, nota-se que não tem sido exigido um "quantum" mínimo de estrutura tecnológica ou agrotécnica como requisito indispensável.

Mas de tudo isto, o importante mesmo, é que não se pode admitir que áreas florestais sejam derrubadas e abandonadas e continuem em abandono enquanto outras áreas de floresta continuam a ser sacrificadas.

Finalmente, torna-se necessário analisar a possibilidade da participação do investidor pequeno. Por exemplo, no cinturão verde das cidades, onde está a maioria da população. Se o grosso da população não está no interior, não é no interior que se situam os problemas da região. O importante e urgente, no caso, é o homem.

\section{ENFATIZAÇÃO DO APROVEITAMENTO}

INTEGRAL DA FLORESTA

Este é um ponto de capital importância e sobre o qual nada se tem feito. Cavacos (wood chips), contraplacados e aglomerados (duratex), polpa, álcool metílico, destilação seca (pirólise) são pơssibilidades apenas sugeridas, ainda não experimentadas. Não há planos pilotos, nesse sentido.

Torna-se muito importante prever o que poderá acontecer com o progressivo aumento da população em decorrência de grandes empreendimentos programados para a região, tais como represas, mineração de ferro, alumínio, estanho e a própria expansão agrícola com a cultura do café e do cacau. Atualmente, a principal atividade é a exploração seletiva de madeiras, isto é, o corte de toras bastante distanciadas uma das outras, de espécies de maior valor, como o cedro e o mogno.

Estes extratores de madeiras, em parte, não possuem terra, trabalham em áreas devolutas e se constituem num elemento de invasão. O seu efeito é diluído mas não deixa de ser prejudicial.
A implantação maciça de grandes projetos de investimento não parece ser ainda aconseIhável. A escolha de alguns empreendimentos prioritários pode ser vantajosa, funcionando como projetos piloto paralelamente aos empreendimentos governamentais.

As experiências de Fordlândia e da Jari podem enquadrar-se nestes casos, como planos piloto paralelos aos projetos governamentais.

O aproveitamento integral de todas as espécies da floresta mista deve ser meta principal e, enquanto não se dispor de dados suficientes sobre a matéria, é aconselhável comedimento, pois a floresta não se deteriora por esperar.

Com os problemas de energia, o alto preço do petróleo, é preciso que se considere, com equilíbrio, o que apresenta a tremenda quantidade de combustível armazenada em três e meio milhões de quilômetros quadrados de floresta da Amazônia brasileira.

Há algum tempo, a SUDAM encomendou a uma Universidade da França (Uhart, 1971). um plano sobre destilação seca da floresta. para obtenção de vários subprodutos e principalmente energia. Seria interessante que esse projeto fosse implantado, pelo menos, como um plano piloto.

Até agora, a quantidade de biomassa que é destruída anualmente, como impossivel de ser aproveitada, constitui um grande prejuízo para a nação e para a humanidade.

Os projetos que estão sendo organizado pela SUDAM, pelo Sistema das Florestas de Rendimento ou Florestas Nacionais, são muito interessantes, mas estão ainda apenas na fase de planejamento, não contam com dados reais.

Muitos desses aperfeiçoamentos que visam a encontrar uma tecnologia apropriada para o aproveitamento da floresta pluvial poderão ser conduzidos na Floresta Naciona! do Tapajós, já em início de implantação.

O ecossistema florestal dos trópicos úmidos é o mais complexo que existe e muito antigo. Suas formações, como já foi referido, são extraordinariamente antigas e por isso muito especializadas face a um processo evolutivo muito demorado, de milhões de anos. Por isso, são formaçōes muito estáveis e mui- 
to especializadas. No entanto, no caso da interferência do homem, a floresta foi levada a uma situação muito delicada e muito perigosa porque é um tipo novo de agente perturbador e ela não poderia orientar a seleção em termos de um agente que não havia existido antes.

\section{MECANISMOS PARA IMPLANTAÇÃO DESSA POLITICA}

DETINIÇÃo E SEPARAÇÃo DAS ÁREAS DE PROBLEMAS ECONÔMICOS E PROBLEMAS DE PRESERVAÇÃo

Até o presente existem diversas áreas de ação se superpondo. As reservas florestais, por exemplo, estão sob jurisdição da SEMA, do IBDF, da FUNAI, de outros órgãos nacionais, estaduais, municipais ou particulares.

PROMOÇÃO DO ESTUDO INTER-DISCIPLINAR EM CADA ÁREA

Tratando-se de matéria complexa logicamente, exigirá estudos sob diversos ângulos, envolvendo as áreas praticamente de todos os Ministérios.

ELABORAÇÃo DO PLANEJAMENTO CENTRAL COM BASE NO ESTUDO INTER-DISCIPLINAR

Somente depois de um preparo difícil, dispendioso e demorado, o sistema central contará com elementos para o planejamento final.
ESTRUTURAÇÃo EFICIENTE E FTRME DA FISCALIZAÇÃo E DO ACOMPANHAMENTO DOS PROJETOS

Esta é uma das partes mais difíceis e uma das mais importantes de tal política e sobre o tópico, referências já foram feitas acima. Até hoje, tem sido muito difícil impedir que a condução de projetos se transforme em processos de invasão. É assunto que exige força e talvez necessite da cooperação das Forças Armadas.

\section{BIBLIOGRAFIA}

KLINGE, H. \& RoDrigues, W. A.

1968 - Litter production in an area of Amazonian terra firme forest. Amazoniana, I; 287-302; 11: $305-310$.

1971 - Matéria orgànica e nutrientes na mata de terra firme perto de Manaus. Acta Amazonica, 1: 69-72.

PRANCE, G. T. \& Elias, T. S. (Editores)

1977 - Extinction is Forewer. New York Botanical Garden, Bronx, New York. 437p.

UHART, E.

1971 - A floresta amazônica, fonte de energia. Belém, SUDAM $91 p$. 